\title{
Bilingual children's lexical strategies in a narrative task*
}

\author{
POLIANA BARBOSA, ELENA NICOLADIS AND \\ MARGAUX KEITH \\ University of Alberta, Canada
}

(Received 23 April 2015-Revised 2 October 2015-Accepted 9 April 2016First published online 30 May 20I6)

\begin{abstract}
We investigated how bilinguals choose words in a narrative task, contrasting the possibilities of a developmental delay vs. compensatory strategies. To characterize a developmental delay, we compared younger (three to five years) and older (seven to ten years) children's lexicalization of target words (Study I). The younger children told shorter stories, omitting many of the target concepts. To characterize compensatory strategies, we compared late second language learning adults to (seven- to ten-year-old) monolingual children (Study 2). The adults often lexicalized the target concepts even when not producing the target words. Finally, we compared French-English bilingual children with French and English monolinguals, all seven to ten years old (Study 3). The bilinguals produced fewer target words than the monolinguals. However, when not producing the target words, the bilinguals often lexicalized the concepts, sharing more in common with the adults (Study 2) in their use of compensatory strategies than with the younger children (Study I). This interpretation was further corroborated by comparisons across studies (Study 4 ).
\end{abstract}

\section{INTRODUCTION}

In language development, bilinguals often lag behind monolinguals of the same age. Bilingual children are not delayed in all aspects of language development relative to monolingual children, but primarily those aspects linked to frequency of exposure in a particular language, such as

[*] This research was supported by a grant from the Social Sciences and Humanities Research Council (SSHRC) to Elena Nicoladis. We thank Cindy Xing for her collaboration. Address for correspondence: Poliana Barbosa, Department of Psychology, University of Alberta, $\mathrm{P}_{2-\mathrm{I}} 7$ Biological Sciences Building, Edmonton AB, T6G 2 9 , CANADA. tel: +I (780) 492-or 24; fax: +I (780) 492-I768; e-mail: poliana@ualberta.ca 
vocabulary (see review in Nicoladis, 2008). Bilingual children often score below the monolingual norm or below same-age monolinguals on vocabulary tests in at least one of their languages (Bialystok, Craik \& Luk, 2007; Bialystok, Luk, Peets \& Yang, 20ıо; Bialystok, Majumder \& Martin, 2003; Junker \& Stockman, 2002; Nicoladis, 2006; Oller, Pearson \& CoboLewis, 2007; Uchikoshi, 2006; Umbel \& Oller, I 994; Umbel, Pearson, Fernández \& Oller, I 992; Verhallen \& Schoonen, I 996). Bilingual children and adults also show greater difficulty in lexical access (i.e. they take longer or make mistakes when accessing specific words in the lexicon for production) than monolinguals (Gollan \& Acenas, 2004; Gollan, Montoya, Cera \& Sandoval, 2008; Yan \& Nicoladis, 2009). Importantly, limited vocabulary may lead to limitations on bilinguals' communicative and conceptual skills (Keith \& Nicoladis, 20I3; Zareva, 2007). The primary purpose of the present study was to investigate bilingual children's strategies in choosing words in the context of a narrative task to document the strength of any relationship between linguistic (vocabulary) deficits, if they are found, and communicative and conceptual skills.

As we will detail below, many previous studies on lexical access have relied on experimental tasks, such as picture-naming or picture-based choice tests. However, there is a discussion in the literature that these standard measures should be interpreted carefully because they are extremely impacted by different cultures and linguistic input (de Villiers, 2004). Unlike these experimental tasks, in narrative tasks there is no necessary correct word. Narratives rely heavily on imagery (Mallan, i996) and are more cognitively complex than these common experimental tasks, given that narratives are intrinsically dependent on the story-teller's causal thinking structure (Trabasso \& Broek, I985). The choice of a term often reflects the story-teller's conception of the story (Downing, I980). Downing showed that monolingual adults commonly used a basic kind term for most nouns when telling a story. However, these adults deviated from basic terms when they were trying to convey an attitude or perspective on the story. In narratives, it is more important to construct a story grammar, i.e. the story-teller needs to represent the narrative events and describe the story units in a sequential order (Herman, 2004; Mandler, I984), than to remember a particular word. Therefore, the selection of what is important to remember and to retell relies on the relationships between narrative events and their representation of the story (Trabasso \& Broek, 1985).

Although several authors have investigated the development of narratives in children (e.g. Pearson, 2002; see also Verhoeven \& Lundquist, 2002), none of them investigated lexical choice in terms of lexicon organization and strategies used to refer to target concepts. As far as we know, Downing (1980) was the only one who investigated lexical choice in narratives in such terms, and then only in a group of monolingual adults. This dearth

$$
830
$$


in the literature does not permit us to make clear predictions about how bilingual children, with greater lexical access difficulties, would choose words differently from monolingual children in the context of a narrative task. Therefore, before we address the principal question guiding this research, we first propose two background studies to allow us to characterize how younger children (Study I) and adult late second language (L2) learners (Study 2) access words in a narrative context. If bilingual children's lexical choices resemble those of younger children, then they could be characterized as demonstrating developmental delay. If their choices resemble those of the adult late L2 learners, then they could be characterized as demonstrating compensatory strategies, but not general communicative delay.

\section{Conceptual delay in lexical access}

Some authors have proposed that lexical organization and retrieval reflect lexical development, and may be a fairer semantic assessment than acquired vocabulary (de Villers, 2004; Seymour, Roeper \& de Villiers, 2005). Previous studies have characterized lexical access differences between bilinguals and same-aged monolinguals as developmental delays (e.g. Keith \& Nicoladis, 20I3). If so, bilingual children with lexical access delay might resemble younger children in their way of choosing words to convey a story. Study I compares three- to five-year-old and seven- to ten-year-old monolingual children. We thought that younger children might be more likely than older children to omit target concepts, either because they cannot access them, or because their story grammars are still rudimentary (Hayes \& Kelly, I985). If so, they might tell shorter stories (i.e. use fewer word tokens to tell the story) and lexicalize fewer target words.

Another possible manifestation of conceptual delay could be observed in children's lexical organization and the non-target word choices. Previous research has suggested that monolingual children's mental lexicons show a shift in relations between words around approximately seven and ten years of age, from primarily schematic to primarily categorical relations (Brown \& Berko, I960; Danovitch \& Keil, 2004; Nelson, I977; Perraudin \& Mounoud, 2009; Sheng, McGregor \& Marian, 2006). Schematic relations are connections established between words when taking into consideration how they follow each other in a discourse or between objects and their relations in the physical word (Perraudin \& Mounoud, 2009). Categorical relations refer to taxonomic relations between words or objects (Perraudin \& Mounoud, 2009; see also Nelson, I977, for a similar conceptualization of the developmental shift in the mental lexicon). For example, if we show children a picture with dog on it and ask them to say the first word that comes to mind, some may give an answer guided by the schematic relation 
like bone (e.g. dogs may be associated with the action of hiding or gnawing on a bone). Others may give an answer showing a categorical relationship with a word like cat, since both cat and dog are from the same taxonomic category, animals. In the context of a narrative task, children who have not yet undergone the schematic-categorical shift might not necessarily use words that could be helpful to the listener's comprehension when they do not produce the non-target word. For example, they might produce nouns with schematic relations to the target words (such as tail for the target cat).

Some studies of simultaneous bilingual children have shown little to no difference from monolinguals for schematic or categorical responses (Namei, 2004; Reustle, 2008; Sheng et al., 2006), and others have found that bilinguals produce more schematic responses than same-aged monolinguals (Keith \& Nicoladis, 2013; see also Verhallen \& Schoonen, I993). Generally these studies used picture-naming or word-association tasks to assess these differences. For instance, one study showed that seven- to ten-year-old simultaneous French-English bilinguals produced more schematically related words on a picture-naming task than monolinguals (Keith \& Nicoladis, 2013). The rate of schematically related words was negatively correlated to children's vocabulary in each of their languages. It is possible that studies have found differing results with simultaneous bilinguals because they can vary in whether their vocabulary size differs or equals that of monolinguals. Consistent with that interpretation, Sheng et al. (2006) found no significant difference in English vocabulary scores between the Mandarin-English bilingual children and the monolingual children, and also no differences between the groups on the rate of schematic-based choices. The link between vocabulary size in a particular language and the schematic-categorical shift could explain why we observe schematic choices in adult and child second language learners. L2 learners have been reported to produce more schematic responses in their $\mathrm{L}_{2}$ than in their $\mathrm{L}_{\mathbf{I}}$, and more than native speakers (Norrby \& Hakansson, 2007; Zareva, 2007). The same pattern of results has been observed with sequential bilingual children (Verhallen \& Schoonen, I993). The use of categorical relations increases as L2 learners' proficiency in L2 increases (Zareva, 2007).

In sum, some researchers have argued that, to the extent that bilingual children show differences from same-aged monolinguals in lexical access, they may be showing a developmental delay. In the context of a narrative task, developmental delay in lexical access could be manifested in the form of shorter stories, fewer instances of lexicalizing particular words, and less frequent use of categorical responses when the non-target word is produced. In Study I, we test whether these characteristics are, indeed, true of younger monolingual children relative to older monolingual children. 


\section{Compensatory strategies for lexical access difficulties}

As noted above, recounting a narrative involves remembering and imaging what one would like to say. Bilingual children might be at least as advanced in the underlying cognitive abilities necessary for narration relative to same-aged monolinguals. For instance, Pearson (2002) showed that, after correcting for multiple analyses, bilingual children performed as well as monolingual children in narrative discursive elements (e.g. mention of key content, event sequence, and reference to characters). If so, when they could not access particular words important for narration, they might use other means to express them. As with many everyday language tasks, speakers could explain what they meant in multiple words (e.g. it goes meow), coin a novel word (the meow-animal), or use categorically related words like a superordinate noun (e.g. animal instead of cat). Study 2 compares intermediate second language learning adults' lexical choice with that of monolingual children in middle childhood. We expected the adults to attempt to lexicalize important concepts in relating the narrative, as opposed to omitting them, but not necessarily with a specific set of target words (as would be required in a picture-naming task).

Some research has shown bilingual advantages in both imagery and creativity over monolinguals (Chuneyeva, 2008; Kachru, I 985; see Simonton, 2008, for review). As noted earlier, narrative tasks rely heavily on imagery and creativity. Bilinguals might use strategies based on imagery and creativity to compensate for lexical access difficulties, thereby showing little to no difference from monolinguals in their choice of words. However, it is worth noticing that many of the studies showing bilingual advantages have only been done with adults, so it is not clear that they will generalize to children.

Finally, in Study 3, to address the principal research question, we compare French-English bilingual children with French and English monolingual children from middle childhood. If bilingual children's lexical choice can be characterized as delayed, then they should show the same patterns of lexicalization as the younger children in Study I. Alternatively, bilingual children's lexical choice might more resemble that of $\mathrm{L}_{2}$ adults, perhaps manifested as compensatory strategies. In Study 4, we make comparisons across studies in order to further investigate bilinguals' closeness to L2 adults and to younger monolingual children.

Although the L2 adults in the present study have Mandarin as their first language $\left(\mathrm{L}_{\mathrm{I}}\right)$, and not French, as the simultaneous bilinguals from Study 3 , it should not matter for the variables under investigation. We are interested in the strategies that the L2 adults will use to retell the narrative in a language in which they potentially cannot access (or do not know) the words for all the key concepts shown in the narrative; not on how the $\mathrm{L}_{\mathrm{I}}$ interferes in $\mathrm{L}_{2}$ performance. 


\section{STUDY I}

METHOD

\section{Participants}

The participants in this study consisted of thirty-four English monolinguals, separated into two age groups. One group was composed of fifteen children aged between three and five years ( 8 boys, 7 girls). The other group included nineteen children between eight and ten years ( 5 boys, I 4 girls). Their average age was, respectively, 3;8 $(\mathrm{SD}=\mathrm{I} ; 92)$, and 8;6 $(\mathrm{SD}=\mathrm{I} ; 0)$.

All the children were living in Edmonton, Alberta, Canada. According to the children's parents, the children had no significant or regular exposure to more than one language. Therefore, the older children had approximately twice the exposure to English than the younger ones.

\section{Materials}

All participants watched the same four-minute excerpt from the non-verbal Pink Panther cartoon In the Pink of the Night. This story shows the Pink Panther being awakened by an annoying cuckoo bird, and the Pink Panther's multiple attempts at trying to get rid of it. The choice of a short cartoon excerpt was meant to not overload the younger children's memory, disentangling vocabulary knowledge from memory effects.

\section{Procedure}

Participants were encouraged to watch the cartoon carefully, as they were going to be asked to describe it to someone later. After viewing the cartoon, they were asked to retell what happened in the cartoon to a researcher.

\section{Transcription and coding}

The children's retelling of the cartoon was transcribed in normal orthography (see supplementary online content for narrative examples, available at $<$ journals.cambridge.org/JCL $>$ ). The length of the stories the children told was counted in word tokens, not counting false starts or self-repetitions. We counted the number of word types the children used in the retelling the whole story, as well as the number of word types within fifty word tokens, as an indicator of the children's vocabulary size. The length limit of fifty word tokens was determined based on the shortest narrative among all the participants across studies.

We also identified thirteen target words (6 nouns and 7 verbs) that were important in telling the story, and then searched the children's stories for if and how they had lexicalized these targets. The target words were: (pink) panther, (cuckoo) clock, bridge, hands (of the clock), (alarm) clock, 
wrench, cuckoos, throws (off the bridge), dives, rows, throws (into the water), goes back (to bed), and hits. Note that the words in parentheses were considered optional in identifying a child's lexicalization as on target. To identify these thirteen words, we started with twenty words generated by the second and third authors that they thought essential to telling the story. We then looked through the transcripts of ten English monolingual adults, retaining the words that were used by six or more.

In analyzing the children's results, we counted only the first mention of each of these concepts. For each child, we calculated the percentage of the thirteen target words that were lexicalized (\% concepts lexicalized). The percentage of concepts lexicalized included both concepts for which the children used the target word and concepts for which they used other words or phrases. The percentage of concepts lexicalized was calculated as the number of lexicalized words divided by thirteen (the total number of opportunities to lexicalize the key concepts).

To calculate whether the children had produced the target form or not, we used as the denominator the number of lexicalized concepts, resulting in the percentage of target forms. So, for instance, if a child lexicalized eight of the targets and six were in the target form, we calculated for that child six out of eight, or $75 \%$ target production.

When the children did not produce the target noun, we coded for use of either (i) nouns that had a categorical relationship with the target, or (ii) other. Nouns that were considered to have a categorical relationship with the target were either nouns from the same semantic category (e.g. tiger for the target panther) or the superordinate category label (e.g. animal for the target panther; see Perraudin \& Mounoud, 2009). The other category most often included nouns with a schematic relation to the target noun (e.g. song for the target cuckoo clock). To calculate the rate of categorical responses, the denominator was the number of lexicalized concepts minus the number of target words. For instance, if a child lexicalized eight of the targets, and four were categorical responses for nouns and one was the target word, we calculated for that child four out of seven ( 8 minus $\mathrm{I}$ ), or $57 \%$, categorical responses.

As discussed above, Study I was designed to characterize what a developmental delay looks like. Therefore, we compared younger and older children's lexical strategies; the latter with twice the time of exposure to English than the former. If the simultaneous bilinguals from Study 3 show any delay, their performance should resemble that of the younger children.

In order to compare our participants groups we used either a $t$-test (or $F$ test in Study 4) when our variables were normally distributed, or the Wilcoxon $W$ test (equivalent of a $t$-test for non-parametric data) when our variables were not normally distributed. 
BARBOSA $E T A L$.

TAB LE I . Average (SD) of word types and tokens, concepts lexicalized, target words used, creative responses, and categorical responses for nouns

\begin{tabular}{lccc}
\hline & Age three-five & Age seven-ten & Adults (Study 2) \\
\hline Word types & $59 \cdot 6(35 \cdot 7)$ & $\mathrm{I} 28 \cdot 5(40 \cdot \mathrm{I})$ & $\mathrm{I} 04 \cdot 4(37 \cdot 34)$ \\
Word tokens & $\mathrm{I} 46 \cdot 6(\mathrm{I} \mathrm{I} 3 \cdot 5)$ & $374 \cdot \mathrm{I}(\mathrm{I} 70 \cdot 7)$ & $303 \cdot 3(\mathrm{I} 62 \cdot 4)$ \\
\# of types in fifty tokens & $27 \cdot 47(3 \cdot 7)$ & $32 \cdot \mathrm{I}(3 \cdot 2)$ & $32 \cdot 8(3 \cdot 0)$ \\
$\%$ concepts lexicalized & $36 \cdot 7(2 \mathrm{I} \cdot 8)$ & $49 \cdot 6(2 \mathrm{I} \cdot 8)$ & $76 \cdot 2(\mathrm{I} \cdot 3)$ \\
$\%$ target total & $25 \cdot 4(27 \cdot 2)$ & $69 \cdot 2(20 \cdot 6)$ & $39 \cdot 0(\mathrm{I} 6 \cdot 2)$ \\
$\%$ creative responses & $0 \cdot 0(0 \cdot 0)$ & $0 \cdot 7(3 \cdot \mathrm{I})$ & $\mathrm{IO} \cdot 3(\mathrm{I} \cdot 6)$ \\
$\%$ categorical responses & $\mathrm{I} 4 \cdot \mathrm{I}(. \mathrm{I} 5)$ & $\mathrm{I} 4 \cdot 7(\mathrm{I} 7 \cdot 6)$ & $22 \cdot \mathrm{I}(\mathrm{I} 4 \cdot 5)$ \\
\hline
\end{tabular}

RESULTS AND DISCUSSION: STUDY I

The two leftmost columns of numbers in Table I summarize the averages of the dependent variables for the younger and older children. There was a significant difference between the groups in terms of total word types $(t(32)=5 \cdot 22, p=.000, d=\mathrm{I} \cdot 8 \mathrm{I})$, word tokens $(t(32)=4 \cdot 44, p=.000, d=$ $\mathrm{I} \cdot 57)$, and the number of types within fifty tokens $(t(32)=3.879, p=\infty$, $d=\mathrm{I} \cdot 33$ ). As would be expected, the older children probably have a larger vocabulary, and therefore they used a significantly higher number of word types and tokens than the younger children. For similar reasons, as shown in Table $\mathrm{I}$, the older children lexicalized more of the target concepts than the younger children, though this difference was only marginally significant $\left(t(32)={ }_{1} \cdot 7 \mathrm{r} 6, p=.09, d=0.59\right)$.

Table $\mathrm{I}$ also summarizes the rate of target-word production. There was a significant difference between the percentage of target words used by the older children when compared to the younger ones $(t(32)=5 \cdot 36, p=\cdot .00)$. As expected, the older children used significantly more target words than the younger children $(d=\mathrm{I} \cdot 82)$.

Table I also shows the average percentage of categorical responses for nouns produced by the children. Although the older children used more categorical responses, the difference was not statistically significant $(W=$ 26 I.50, n.s.).

In a final set of analyses we used Spearman's correlation to investigate the relationship between (a) the rate of categorical responses and (b) the children's age, word types, and types within fifty tokens. We only found a marginally significant, and negative, correlation between types within fifty tokens and categorical responses $(\rho=-0.4 \mathrm{I} 2, p=.080)$; this was true only for the older children. Thus, the greater the number of types within fifty tokens, the lower the rate of categorical responses produced by the children.

In summary, in comparison to older children, younger children's production of target words in a narrative context could be characterized as OMIssive. They told shorter stories with less varied word types than older

$$
836
$$


children. They also lexicalized fewer of the target concepts than older children and produced fewer target items. When producing categorical responses for nouns, the younger children and older children did not differ. If bilingual children show delay in lexical choice and lexicon organization, they may also show an omissive narrative style.

\section{STUDY 2}

METHOD

\section{Participants}

The participants in this study consisted of the same nineteen English monolingual children ( 5 boys, I 4 girls), all aged between seven and ten years, who participated in Study I, and fifteen Mandarin Chinese-speaking adults who were learning English as their second language (8 men, 7 women), all aged between twenty-eight and thirty-nine years. The participants' average ages were, respectively, 8;6 ( $\mathrm{SD}=\mathrm{I} ; 0)$, and $33 ; 4$ $(\mathrm{SD}=3 ; 36)$.

The adult late $\mathrm{L}_{2}$ learners grew up in mainland China and they started to speak English fluently when they moved, as adults, to countries where English was the predominant spoken language. All of the adults had begun their intensive English-learning post-adolescence. At the time of the study, all of the adults had spent at least one year $(\mathrm{M}=4 ; 6, \mathrm{SD}=3 ; 4)$ in an English-predominant part of the world. On the basis of listening to the narratives, all the Chinese adults were classified as INTERMEDIATE SPEAKERS by an experienced English as a second language teacher. There was no significant correlation between years of exposure to English and the number of word types (within fifty tokens) the adults used when retelling the story. More importantly, there was no difference between the groups on the number of word types produced within fifty tokens.

\section{Materials and procedure}

We followed the same materials and procedure as in Study I, with two exceptions. First, the adult late L2 learners watched the Pink Panther cartoon twice and retold the story once in Chinese and once in English (there were no differences between the English narratives of the adults who did the retelling first in English versus those of the adults who did the English retelling after they did it in Chinese). The order of the two language sessions was counterbalanced. The two language sessions were done on different days, usually about a week apart, with a native speaker experimenter. We report here only on the adults' L2 English stories.

Second, in analyzing the adults' responses, we noticed a fair number of what we called CREATIVE responses (e.g. a little bird which makes the clock 
as his home, when referring to the cuckoo clock; or bought a flower and tried to use the flower to miss the bird, when referring to the Pink Panther throwing flowers on the river after thinking the bird was dead). Creative responses were understood as the participants' effort to convey through original expressions the target concepts that they do not have a word for, or could not access. These expressions were functional in that they did not interfere with narrative clarity (see supplementary online content). Because creativity can be defined as original and functional ideas (Simonton, 2008), we identified such responses as creative, and not circumlocution (e.g. of non-creative circumlocution: this guy who looked, looks like tiger but except it doesn't look like him. I mean his colours. He doesn't have the same colours on his body, when referring to the Pink Panther; or and there is someone at the door and there was something that makes noise, when referring to the cuckoo clock). We report here the percentage of creative responses (the number of creative responses divided by the number of lexicalized concepts minus the number of target words) for both the children in Study I and the adults (see Table I).

Study 2 was designed to characterize what compensatory strategies simultaneous bilinguals could use to overcome lexical access and lexical choice difficulties. Therefore, we compared the lexical strategies used by L2 adults with an average time of exposure similar to the younger children in Study I, and by seven- to ten-year-old monolingual children; the latter with the same time of exposure to English as the simultaneous bilinguals in Study 3 .

\section{RESULTS AND DISCUSSION: STUDY 2}

The two rightmost columns in Table I summarize the averages of the dependent variables for the children and the adults. Although the children tended to produce more word types and tokens than the adults, there was only a marginally significant difference between them in terms of total word types $(t(32)=\mathrm{I} .794, p=.082, d=0.60)$, and a non-significant difference of word tokens $\left(t(32)=x_{1} \cdot 226\right.$, n.s. $)$. No difference was found for the number of types within fifty words $(t(32)=0.646$, n.s. $)$. As also shown in Table $\mathrm{I}$, the adults attempted to lexicalize significantly more of the target concepts than the children $\left(t(32)=4 \cdot 27, p=\cdot 000, d={ }_{1} \cdot 53\right)$. Even though the adults tended to use fewer word types in telling the whole story than the children, they nonetheless attempted to lexicalize most of the target words.

However, lexicalizing and producing the target words were not the same. When controlling for the number of concepts lexicalized, the children used significantly more target words than the adults $(t(32)=4 \cdot 65$, $\left.p=. \circ 0 \circ, d={ }_{\mathrm{r}} \cdot 6_{3}\right)$. However, the adults used marginally more categorical responses for nouns than the children $\left(W=286 \cdot 5, p=\cdot{ }_{10}\right)$.

$$
838
$$


Regarding the participants' creativity when referring to the target words, the adults were more CREATIVE than the seven- to ten-year-olds ( $W=255^{\circ}$, $p=.006)$. This finding reinforces the idea that the adults were indeed making an effort to convey the meaning of the target concept, despite not knowing the correct word for it or not being able to access it.

Finally, we ran a Spearman's correlation test between the rate of categorical responses for nouns and the participants' age, word types, and types within fifty tokens. While, for the adults, word types and word tokens were significantly correlated to categorical responses (respectively $\rho=-0.588, p=.02 \mathrm{I}$, and $\rho=-0.59 \mathrm{I}, p=.020$ ); for the children we found only a marginally significant correlation between types within fifty tokens and categorical responses $(\rho=-0.4 \mathrm{I} 2, p=.080)$. All correlations were negative, i.e. the greater the number of types, tokens, and types within fifty tokens, the lower the number of categorical responses produced by the participants.

In summary, the adult late L2 learners showed more compensatory strategies than the children. Even though the adults tended to tell shorter stories, using less varied words than the children, they nonetheless attempted to lexicalize most of the target concepts. The adults also showed a greater proportion of categorical responses for nouns than the children, and a greater use of creative responses, coining terms or explaining the target concept's meaning. In Study 3, we test whether bilingual children also show these patterns of compensatory strategies to lexical access delay.

\section{STUDY 3}

METHOD

\section{Participants}

The participants in this study consisted of nineteen French-English bilinguals ( 9 boys, ro girls), fourteen French monolinguals ( 7 boys, 7 girls), and nineteen English monolinguals ( 5 boys, I 4 girls), all aged between seven and ten years. The average age of the bilinguals was 8;7 $(\mathrm{SD}=0 ; 9)$. The average age of the French monolinguals was $8 ; 5(\mathrm{SD}=0 ; 8)$, and of the English monolinguals, 8;6 ( $\mathrm{SD}=\mathrm{r} ; \mathrm{O})$. The monolingual English group was the same as the older children in Study I and the children in Study 2. The bilinguals did not differ significantly in age from either of the monolingual groups $\left(F_{\mathrm{S}}<\mathrm{I}\right)$, nor did the monolinguals differ in age $(F<\mathrm{I})$.

Both the English monolinguals and the French-English bilinguals were living in an English-speaking city, Edmonton, Alberta, Canada. The bilinguals were simultaneous bilinguals, with one French-speaking parent at home and one English-speaking parent at home. The bilinguals were all attending French schools. The French monolinguals lived in a small 
TA B LE 2. Average (SD) of word types and tokens, concepts lexicalized, target words used, creative responses, and categorical responses for nouns for seven- to ten-year-old children

\begin{tabular}{|c|c|c|c|c|}
\hline & $\begin{array}{l}\text { Monolingual } \\
\text { (English) }\end{array}$ & $\begin{array}{l}\text { Bilingual } \\
\text { (English) }\end{array}$ & $\begin{array}{l}\text { Bilingual } \\
\text { (French) }\end{array}$ & $\begin{array}{l}\text { Monolingual } \\
\text { (French) }\end{array}$ \\
\hline Word types & $\mathrm{I} 28 \cdot 5(4 \mathrm{O} \cdot \mathrm{I})$ & I $42 \cdot 9(47 \cdot 2)$ & I $56 \cdot 5(40 \cdot 9)$ & $127 \cdot 4(35 \cdot 5)$ \\
\hline Word tokens & $374 \cdot 1(170 \cdot 7)$ & $487 \cdot 9(242 \cdot I)$ & $495 \cdot 9\left(\right.$ I $\left._{54 \cdot 5}\right)$ & $385.6(\mathrm{I} 65.2)$ \\
\hline \# of types in fifty tokens & $32 \cdot$ I I $(3 \cdot 2)$ & $30 \cdot 89(4 \cdot 0)$ & $32 \cdot 26(5 \cdot 6)$ & $3 \mathrm{I} \cdot 36(2 \cdot 6)$ \\
\hline$\%$ concepts lexicalized & $49 \cdot 6(2 \mathrm{I} \cdot 8)$ & $65 \cdot 6(18 \cdot 2)$ & $7 \mathrm{I} \cdot 3(19 \cdot 2)$ & $56 \cdot 0($ I $9 \cdot 4)$ \\
\hline$\%$ target total & $69 \cdot 2(20 \cdot 6)$ & $49.5(19.7)$ & $36 \cdot 6(15 \cdot 2)$ & $27.9(19.9)$ \\
\hline$\%$ creative responses & $0.7(3 \cdot 1)$ & $5 \cdot 4(10 \cdot 9)$ & I0.9 $(9 \cdot 6)$ & $9 \cdot I_{5}(8 \cdot 5)$ \\
\hline$\%$ categorical responses & $14.7(17 \cdot 6)$ & I $9.6(\mathrm{I} 2 \cdot 8)$ & I $2.5($ I 3.4$)$ & I $7.8(14.9)$ \\
\hline
\end{tabular}

French-speaking city close to Montreal, Quebec, Canada. According to the children's parents, while the English and French monolinguals had no significant or regular exposure to more than one language, the bilinguals had been hearing both languages since birth.

\section{Materials and procedure}

The same procedures adopted in Study I were used here with only one exception, the bilinguals watched the cartoon and retold the story twice: once in French and once in English, on different days and with different native-speaker interlocutors (see supplementary online content for narrative examples). The order of the language sessions was counterbalanced, and there were no differences between the English narratives of the children who did the retelling first in English versus those of the children who did the English retelling after they did it in French. There were at least two days, and usually a week, between the two language sessions.

Study 3 was designed to compare the lexical strategies (possibly COMPENSATORY strategies versus OMIssive narrative style) used by simultaneous bilinguals to those used by monolinguals of the same age.

\section{RESULTS AND DISCUSSION: STUDY 3}

Table 2 summarizes the averages of the dependent variables. In English, there was no significant difference between the groups in terms of word types $\left(t\left(3^{6}\right)=\mathrm{I}_{\mathrm{I}} \cdot 02\right.$, n.s. $)$, word tokens $\left(t\left(\mathrm{I}_{3} 6\right)=_{\mathrm{I}} \cdot 67, p=\cdot \mathrm{I}_{0}\right)$, and number of types within fifty words $(t(36)=\mathbf{r} \cdot 2 \mathrm{I}$, n.s.). In French, the bilinguals used a significantly higher number of word types than the monolinguals $(t(3 \mathrm{I})=2 . \mathrm{I} 3, p=.04 \mathrm{I}, d=0.76)$, and also tended to use more word tokens $\left(t(3 \mathrm{I})=_{\mathrm{I}} \cdot 97, p=.058\right)$. However, the groups did not differ in the number

$$
840
$$


of types within fifty tokens $(t(32)=0 \cdot 558$, n.s. $)$. Table 2 also summarizes the percentage of our target concepts that the children lexicalized. The bilinguals lexicalized a higher rate of concepts than the monolinguals in both languages $(t(3 \mathrm{I})=2.4 \mathrm{I}, p=.032, d=0.79$, and $t(36)=2.45, p=.0 \mathrm{I} 9, d=0.80$, for French and English, respectively).

Table 2 also summarizes the rate of target-word production. While English monolinguals used significantly more target words than the English bilinguals $(t(36)=3.02, p=.005, d=0.98)$, in French the difference was not significant $(t(3 \mathrm{I})=\mathrm{I} \cdot 09$, n.s. $)$.

Regarding the average rate of categorical responses for nouns, in English, although the bilinguals used more categorical responses than the monolinguals, the difference was not statistically significant $(W=334 \cdot 5 \circ$, n.s.). In contrast, in French, monolingual children seemed to use more categorical responses than bilinguals, but once again this difference did not reach statistical significance $(W=286 \cdot 5 \circ$, n.s. $)$.

As a creativity measure, we also counted the number of coinages and explanations (see the 'Method' section of Study 2) used by the children. In Table 2 we can see that the bilingual children in English tended to use more CREATIVE responses than the English monolingual children. Indeed, this difference was marginally significant $(W=332 \cdot 0, p=\cdot 077)$. However, no significant difference was found in French $(W=310 \cdot 0$, n.s.).

We also compared the French monolingual and the English monolingual children. While English monolingual children used significantly more target words than the French monolinguals $(t(3 \mathrm{I})=5.79, p=.000, d=2 \cdot 04)$, the later used a higher proportion of creative responses than the former $\left.(t)_{3} \mathrm{I}\right)=$ $4.33, p=.000, d=\mathrm{I} \cdot 4 \mathrm{I})$. The groups did not differ in their number of word types and tokens or their number of types within fifty words; there were also no significant differences in how much they tried to lexicalize the target concepts, or in their rate of categorical response. Therefore, we cannot characterize either of the monolingual groups as using an OMIssive narrative style or a COMPENSATORY strategy when retelling the stories.

Finally, we correlated the coefficients for the rate of categorical responses for nouns, with children's age, word types, and types within fifty tokens. For the English bilinguals, a significant correlation was found between word types and categorical responses $(\rho=0.536, p=.018)$ and between word tokens and categorical responses $(\rho=0.489, p=.034)$. For English monolinguals we only found a marginally significant correlation between word types within fifty tokens and categorical responses $(\rho=-0.4 \mathrm{I} 2$, $p=.080$ ). Finally, no significant correlation was found for the French monolingual and the French bilingual group.

In summary, the bilingual children's lexical choice cognitive strategies resembled the adult late $\mathrm{L}_{2}$ learners (in Study 2) more closely than that of the younger children (in Study $\mathrm{I}$ ). The bilingual children did not omit 
more target concepts than the monolingual children: instead, they tended to tell slightly longer stories with slightly more varied words than the monolinguals in both languages. The bilinguals also tended to lexicalize more concepts than monolinguals in both languages. Consistent with lexical access difficulties, the bilinguals tended to use fewer target nouns than the monolinguals in English; however, this difference was not found in French. Despite using fewer target words in English, the bilinguals used a very high percentage of non-target nouns with categorical relations with the targets (e.g. animal for panther) and creative responses. In many respects, the bilingual children's approach to having greater difficulty accessing particular target words relative to the monolinguals could be characterized as using compensatory strategies, like the adult late L2 learners in Study 2.

As an attempt to further investigate the closeness of bilinguals' lexical strategies to those of adult late L2 learners, Study 4 directly compares the groups from the previous studies.

\section{$\mathrm{STUDY}_{4}$}

METHOD

\section{Participants}

The French-English bilinguals in Study 3, the younger English monolingual children in Study $\mathbf{I}$, and the adult late L2 learners from Study 2 were compared in this study. See description of the participants in the studies above.

\section{Materials and procedures}

See description on the studies above.

RESULTS AND DISCUSSION: STUDY 4

The following analyses were made for the bilinguals' English narrative, and then for their French narrative. The dependent variables were always the number of word types and tokens, the number of types within fifty tokens, the rate of lexicalized concepts, the proportion of target words, the proportion of categorical responses for nouns, and creative responses.

\section{Bilinguals' English narrative}

A MANOVA showed that the three groups (English bilinguals, Adult L2, and younger English monolingual children) differed in their total word tokens and types (respectively, $F(2,46)=$ I 7.3 I, $p=.000, \eta_{p}^{2}=.429$; $\left.F(2,46)=\mathrm{I} 4 \cdot \mathrm{I} 7, p=.000, \eta_{p}^{2}=\cdot 38 \mathrm{I}\right)$, number of types within fifty tokens 
$\left(F(2,46)=8.354, \quad p=.00 \mathrm{I}, \eta_{p}^{2}=.266\right)$, the rate of lexicalized concepts $\left(F(2,46)=20 \cdot 25, p=.000, \eta_{p}^{2}=\cdot 468\right)$, and target words $(F(2,46)=5 \cdot 34 \mathrm{I}$, $\left.p=.008, \eta_{p}^{2}=\cdot_{\mathrm{I}} 88\right)$. Further pairwise comparisons showed that in English, the bilinguals from Study 3 had a greater number of total word types and tokens than both the younger English monolingual children from Study I and the adult late L2 learners from Study 3 (all $p s<.05$ ). Regarding the number of types within fifty tokens, the bilingual children and the adult late L2 learners did not differ, but both groups had a higher number of types (within fifty tokens) than the younger children (respectively, $p=.025$ and $p=.00 \mathrm{I})$. The bilinguals from Study 3 were also shown to lexicalize more concepts and to use more target words than the younger children from Study I (all $p$ s $<.05$ ); the bilinguals' performance did not differ from that of the adult late $\mathrm{L}_{2}$ learners.

Compared to the younger children from Study I, while the bilinguals used more creative responses $(W=225, p=.035)$, they did not use more categorical responses for nouns $(W=232 \cdot 5$, n.s. $)$. In relation to the adult late L2 learners from Study 2, the bilinguals did not differ in their use of categorical responses for nouns ( $W=3$ I9.0, n.s.); however, a marginal significant difference was found for adults using more creative responses than the bilingual children $(W=290 \cdot 5, p=\cdot \mathrm{IO})$.

\section{Bilinguals' French narrative}

A MANOVA showed that the three groups (French bilinguals, Adult L2, and younger English monolingual children) differed in their word tokens and types, and types within fifty tokens (respectively, $F(2,46)=27 \cdot 12$, $p=.000, \quad \eta_{p}^{2}=.54 \mathrm{I} ; \quad F(2,46)=24.39, \quad p=.000, \quad \eta_{p}^{2}=.5$ I $5 ; \quad F(2,46)=6.863$, $\left.p=.002, \eta_{p}^{2}=.5 \mathrm{I}_{5}\right)$. The groups also significantly differed in their proportion of lexicalized concepts $\left(F(2,46)=2 \mathrm{I} \cdot 80, p=\cdot 000, \eta_{p}^{2}=\cdot 487\right)$, but not in the proportion of target words used $\left(F(2,46)={ }_{1} \cdot 83\right.$, n.s.). Further pairwise comparisons showed that, in French, the bilinguals from Study 3 had a greater number of word types and tokens than both the younger English monolingual children from Study I and the adult late L2 learners from Study 3 (all $p s<.05$ ). Regarding the number of types within fifty words, the bilingual children and the adult late L2 learners did not differ, but both groups had a higher number of types (within fifty words) than the younger children (respectively, $p=.003$ and $p=.002$ ). The bilinguals from Study 3 were shown to lexicalize more concepts only than the younger children from Study I (all $p s<.05$ ); the bilinguals' performance did not differ from that of the adult late L2 learners.

Compared to the younger children from Study I, while the bilinguals used more creative responses $(W=\mathrm{I} 80.0, p=.00 \mathrm{I})$, they did not use more categorical responses for nouns $(W=324 \cdot 0$, n.s. $)$. In relation to the adult 
late L2 learners from Study 2, the bilinguals did not differ in their use of creative responses $(W=330 \cdot 5$, n.s. $)$; however, a significant difference was found for the adults using more categorical responses for nouns than the children $(W=275 \cdot 0, p=\cdot 047)$.

Summarizing, the bilingual children from Study 3 used a greater number of word types and tokens, and types within fifty words, than both the younger children from Study I and the adult late L2 learners from Study 2. The bilinguals lexicalized more concepts, in English and in French, than the younger children, but not than the adults. While in French, the bilinguals tended to use more creative responses than the younger children, in English, they tended to use more categorical responses for nouns. Finally, the bilinguals tended to use almost the same proportion of categorical (in English) and creative responses as the adults. Therefore, these results are further evidence that, in both French and English, the bilinguals more closely resemble the adult late L2 learner than the younger children, suggesting that they are able to compensate for difficulties in accessing and choosing (target) words, retelling a narrative in a mature, conceptually advanced way.

\section{GENERAL DISCUSSION}

Previous research has shown that bilingual children present a smaller vocabulary and score below the norm in at least one of their languages when compared to monolinguals of the same age (Bialystok, 2009; Bialystok et al., 2007; Bialystok et al., 2003; Junker \& Stockman, 2002; Nicoladis, 2006; Oller et al., 2007; Uchikoshi, 2006; Umbel \& Oller, I 994; Umbel et al., I992; Verhallen \& Schoonen, I996). Bilinguals also show greater lexical access difficulties relative to monolinguals (Yan \& Nicoladis, 2009).

Given such lexical access difficulties, the primary objective of the present set of studies was to investigate how bilingual children choose words (i.e. the lexical strategies used) in a narrative task compared to same-age monolinguals. To characterize what a lexical choice delay might look like, we first compared lexical choices in narratives between younger and older children in Study I. Younger children told shorter stories and lexicalized fewer of the target concepts than older children did. We characterized these differences as an omissive narrative style. In Study 2, we compared the lexical choices of $\mathrm{L}_{2}$ adults with those of monolingual children between seven and ten years of age. The adults lexicalized most of the target concepts, but rarely with the target words. Instead, the adults often used nouns with a categorical relation to the target (e.g. cat for the target panther). They also coined new words or explained what they meant more often than the children did when they did not produce the target form.

$$
844
$$


As for the bilingual children in Study 3, their performance did not resemble the OMISSIVE narrative style observed in the younger monolingual children in Study I. The bilingual children tended to tell longer stories with equal or more varied vocabulary (even within a set number of tokens) than the same age monolingual children. They also tended to lexicalize more target concepts than the monolingual children. These results are surprising, given the common finding in the literature that bilingual children perform more poorly on vocabulary tests in at least one of their languages. Although vocabulary scores on standardized tests and word types or word types within a set number of tokens in a narrative task are not the exactly the same construct, the latter two can be considered proxies to vocabulary. Similarly to Keith and Nicoladis (2013), who found that their participants' vocabulary scores were correlated with their rate of schematic responses, in this study we found for some groups that the number of word types or word types within fifty tokens was correlated with the participants' rate of categorical responses and age.

Finally, in Study 4 we showed that both in French and English, the bilingual children used more types and tokens, had a greater number of types within fifty words, a greater rate of creative responses, and lexicalized more target concepts than the younger children in Study I. The bilinguals also produced a higher number of types and tokens than the adult late L2 learners, but did not differ in their number of word types within fifty tokes and their use of categorical and creative responses. These findings are further evidence that the performance of the bilingual children in Study 3 resembles more closely that of the adult late $\mathrm{L}_{2}$ learners than that of younger children.

As with previous research showing that bilinguals have a harder time with lexical access than monolinguals (e.g. Yan \& Nicoladis, 2009), the bilinguals in Study 3 did tend to use fewer target forms than the monolinguals, although this difference was significant only in English. However, unlike in Keith and Nicoladis (2013), where bilingual children used fewer categorical responses for nouns than monolinguals, the bilingual children in this study showed the opposite pattern. That is, they tended to use more categorical responses than monolinguals (see also Namei, 2004; Reustle, 2008). One possible reason for the opposite patterns in these studies is the motivation and/or cognitive resources for the task. That is, if asked to name the picture of a panther (the kind of task in Keith \& Nicoladis, 2013), children might be satisfied with responses like tail or ferocious or roar, responses that are schematically associated with the target. In contrast, in a narrative, calling the main character panther a tail will fundamentally disrupt the story-line, while animal or lion would be sufficient to convey the thrust of the story.

Another explanation for the bilinguals' higher performance is that the narrative retelling task used is very likely less culture bound than the 
traditional picture-based choice tasks (see de Villiers, 2004, for a discussion). Instead of simply word meaning, we evaluated children's semantic knowledge through lexical organization and retrieval, offering the bilinguals an opportunity to compensate for lexical access difficulties.

While bilingual children's language development has often been characterized in terms of delays relative to monolingual children (Bialystok, 2009; Genesee \& Nicoladis, 2007), the present results suggest that that characterization may be restricted to only some measures of language development. In the context of a narrative, in which there is a strong reliance on imagery and less call for a particular correct response, bilingual children showed use of some advantages over monolinguals (e.g. tendency to tell longer stories with more varied vocabularies) and some compensatory strategies (e.g. high use of nouns categorically related to the target word and a tendency to use more creative words) to get their story across. They seemed to have overcome their lexical access difficulties, showing no lag in lexical choice when compared to monolingual of the same age.

An important limitation of this study was its sample sizes. Future research is needed to confirm these findings and to test their generalizability to other bilingual populations. As there are cross-cultural differences in many aspects of narrative (see, for example, Anstatt, 2008; Kupersmitt \& Berman, 200 I), the present results may not necessarily generalize to speakers of all languages. For instance, in this study, the narrative in French, for both bilingual and monolingual children, contained fewer target words than English narratives, but more categorical and creative responses. Although these differences did not always reach statistical significance, they may reflect cross-cultural differences. For instance, English narrative style could be more factual, while the French could be more descriptive; or such differences could be a result of the target words being based on English monolingual adults' retelling of the Pink Panther's cartoon (as described in Study I). Similarly, this could also explain the adult late L2 learners' higher rates of categorical and creative responses when compared to monolingual children (Study 2).

Another limitation of the present study is that we did not have vocabulary scores for the bilingual children. Bilingual children of age eight to ten generally show lower vocabulary scores than monolinguals in at least one of their languages (Oller et al., 2007; Umbel \& Oller, I994; Umbel et al., I 992). We know of no reports that bilingual children can score better than monolinguals in both their languages, as might be concluded by the tendency of the bilingual children in Study 3 to use more word types in both languages relative to monolinguals. Future studies can measure vocabulary scores and elicit narratives from the same bilinguals to verify how the two kinds of measures are related. 
Although we chose a short excerpt from Pink Panther cartoon, one might think that the differences found between younger and old children in Study I were due to memory load differences (e.g. the number of episodes remembered) and not to vocabulary knowledge. We do not believe this is the case, because our analyses were focused on a few target words that represented key characters and objects in the story, and not on minimal details. Nevertheless, future studies could further investigate this issue by adding memory load measures and statistically controlling for that in their analyses.

In spite of these limitations, these studies have provided preliminary evidence that, in a narrative context, bilingual children can compensate for lexical access difficulties, resulting in lexicalization of key concepts to communicate the story. For these children, a smaller lexicon was shown not to be an indicator of poorer performance, even on a task that relies on the lexicon.

\section{SUPPLEMENTARY MATERIALS}

For supplementary materials for this paper, please visit journals/cambridge. org/JCL.

\section{REFERENCES}

Anstatt, T. (2008). Aspect and tense in storytelling by Russian, German and bilingual children. Russian Linguistics 32, $\mathrm{I}-26$.

Bialystok, E. (2009). Bilingualism: the good, the bad, and the indifferent. Bilingualism: Language and Cognition 12, 3-1 1 .

Bialystok, E., Craik, F. I. M. \& Luk, G. (2007). Lexical access in bilinguals: effects of vocabulary size and executive control. Fournal of Neurolinguistics 21, 522-38.

Bialystok, E., Luk, G., Peets, K. F. \& Yang, S. (2010). Receptive vocabulary differences in monolingual and bilingual children. Bilingualism: Language and Cognition 13, 525-3 I.

Bialystok, E., Majumder, S. \& Martin, M. M. (2003). Developing phonological awareness: Is there a bilingual advantage? Applied Psycholinguistics 24, 27-44.

Brown, R. \& Berko, J. ( 1960 ). Word association and the acquisition of grammar. Child Development 3I, I-I 4 .

Chuneyeva, A. (2008). Assessing cognitive functions in Russian-English bilinguals and English monolinguals using visual spatial tasks. Unpublished doctoral dissertation, Carlos Albizu University.

Danovich, J. H. \& Keil, F. C. (2004). Should you ask a fisherman or a biologist? Developmental shifts in ways of clustering knowledge. Child Development 75, 91 8-31.

de Villiers, J. (2004). Cultural and linguistic fairness in the assessment of semantics. Seminars in Speech and Language 25, 73-90.

Downing, P. (1980). Factors influencing lexical choice in narrative. In W. Chafe (ed.), The pear stories: cognitive, cultural, and linguistic aspects of narrative production, 89-126. Norwood, NJ: ABLEX Publishing Company.

Genesee, F. \& Nicoladis, E. (2007). Bilingual first language acquisition. In E. Hoff \& M. Shatz (eds), Handbook of language development, 324-42. Malden, MA: Blackwell Publishing. 
Gollan, T. H. \& Acenas, L.-A. R. (2004). What is a TOT? Cognate and translation effect on tip-of-the-tongue states in Spanish-English and Tagalog-English bilinguals. Fournal of Experimental Psychology: Learning, Memory, and Cognition 3o, 246-69.

Gollan, T. H., Montoya, R. I., Cera, C. \& Sandoval, T. C. (2008). More use almost always means a smaller frequency effect: aging, bilingualism and the weaker links hypothesis. Fournal of Memory and Language 58, 787-8I 4 .

Hayes, D. \& Kelly, S. B. (1985). Sticking to syntax: the reflection of story grammar in children's and adults' recall of radio and television shows. Merrill-Palmer Quarterly 31, 345-6o. Online: <http://digitalcommons.library.umaine.edu/psy_facpub/r2>.

Herman, D. (2004). Story logic. Lincoln, NE: University of Nebraska Press.

Junker, D. A. \& Stockman, I. J. (2002). Expressive vocabulary of German-English bilingual toddlers. American Fournal of Speech-Language Pathology II, 38 I-94.

Kachru, B. B. (1985). The bilinguals' creativity. Annual Review of Applied Linguistics 6, 20-33.

Keith, M. \& Nicoladis, E. (20I3). The role of within-language vocabulary size in children's semantic development: evidence from bilingual children. Fournal of Child Language 4o, $873-84$.

Kupersmit, J. \& Berman, R. A. (200I). Linguistic features of Spanish-Hebrew children's narratives. In L. Verhoeven \& S. Strömqvist (eds), Narrative development in a multilingual context. Philadelphia, PA: John Benjamins.

Mallan, K. (I996). The road less traveled: storytelling and imaginative play. Storytelling World 9, 22-3.

Mandler, J. M. (1984). Stories, scripts, and scenes: aspects of schema theory. Hillsdale, NJ: Lawrence Erlbaum.

Namei, S. (2004). Bilingual lexical development: a Persian-Swedish word association study. International Yournal of Applied Linguistics 14, 363-88.

Nelson, K. (1977). The syntagmatic-paradigmatic shift revisited: a review of research and theory. Psychological Bulletin 84, 93-1 I6.

Nicoladis, E. (2006). Cross-linguistic transfer in adjective-noun strings by preschool bilingual children. Bilingualism: Language and Cognition 9, I 5-32.

Nicoladis, E. (2008). Why does bilingualism affect language and cognitive development? In J. Altarriba \& R. Heredia (eds), An introduction to bilingualism: principles and practices, I67-8I. Mahwah, NJ: Lawrence Erlbaum.

Norrby, C. \& Hakansson, G. (2007). Girl-lass or curl? Word associations in second language learners. Australian Review of Applied Linguistics, 30, 22 1 I-22. I 7.

Oller, D. K., Pearson, B. Z. \& Cobo-Lewis, A. B. (2007). Profile effects in early bilingual language and literacy. Applied Psycholinguistics 28, 19I-230.

Pearson, B. Z. (2002). Narrative competence among monolingual and bilingual school children in Miami. In D. K. Oller \& R. E. Eilers (eds), Language and literacy in bilingual children, I35-74. Bristol: Multilingual Matters.

Perraudin, S. \& Mounoud, P. (2009). Contribution of the priming paradigm to the understanding of the conceptual developmental shift from 5 to 9 years of age. Developmental Science I2, 956-77.

Reustle, C. (2008). The effect of $L_{I}$ on the syntagmatic-paradigmatic shift. Unpublished master's thesis, William Patterson University of New Jersey.

Seymour, Roeper \& de Villiers (2005). Diagnostic Evaluation of Language Variation-Norm Referenced. San Antonio, TX: Pearson Assessments, Inc.

Sheng, L., McGregor, K. K. \& Marian, V. (2006). Lexical-semantic organization in bilingual children: evidence from a repeated word associate task. Fournal of Speech, Language, and Hearing Research 49, 572-87.

Simonton, D. K. (2008). Bilingualism and creativity. In J. Atarriba \& R. R. Heredia (eds), An introduction to bilingualism: principles and process, 147-66. Mahwah, NJ: Laurence Erlbaum.

Trabasso, T. \& van den Broek, P. (1985). Causal thinking and the representation of narrative events. Fournal of Memory and Language 24, 6r 2-30. 


\section{BILINGUAL LEXICAL CHOICE}

Uchikoshi, Y. (2006). English vocabulary development in bilingual kindergartners: What are the best predictors? Bilingualism: Language and Cognition 9, 33-49.

Umbel, V. M. \& Oller, D. K. (I994). Developmental changes in receptive vocabulary in Hispanic bilingual school children. Language Learning 44, 22 I-42.

Umbel, V. M., Pearson, B. Z., Fernández, M. C. \& Oller, D. K. (I992). Measuring bilingual children's receptive vocabularies. Child Development 63, Iо г 2-20.

Verhallen, M. \& Schoonen, R. (1993). Word definitions of monolingual and bilingual children. Applied Linguistics 14, 344-65.

Verhallen, M. \& Schoonen, R. (I996). Lexical knowledge in Li and L2 of third and fifth graders. Applied Linguistics $\mathbf{1 9}, 452-70$.

Verhoeven, L. \& Lundquist, S. (2002). Narrative development in a multilingual context. Amsterdam: John Benjamins.

Yan, S. \& Nicoladis, E. (2009). Finding le mot juste: differences between bilingual and monolingual children's lexical access in comprehension and production. Bilingualism: Language and Cognition 12, 323-35.

Zareva, A. (2007). Structure of the second language mental lexicon: How does it compare to native speakers' lexical organization? Second Language Research 23, I23-53. 